\title{
Perceptions of pre-clerkship medical students and academic advisors about sleep deprivation and its relationship to academic performance: a cross-sectional perspective from Saudi Arabia
}

Lama AIFakhri, Jumana Sarraj, Shouq Kherallah, Khulood Kuhail, Akef Obeidat and Ahmed Abu-Zaid*

\begin{abstract}
Background: The medical student population is believed to be at an increased risk for sleep deprivation. Little is known about students' perceptions towards sleep deprivation and its relationship to academic performance. The aim of study is to explore the perceptions of medical students and their academic advisors about sleep deprivation and its relationship to academic performance.

Methods: The study took place at Alfaisal University, College of Medicine, Riyadh, Saudi Arabia. An online, anonymous, cross-sectional, self-rating survey was administered to first-, third-year students and their academic advisors. Two-tailed Mann-Whitney $U$ test was used to compare the mean 5-point Likert scale responses between students according to gender, academic year and cumulative grade point average (cGPA).

Results: A total of 259 students and 21 academic advisors participated in the survey (response rates: 70.6 and $84 \%$, respectively). The vast majority of students agreed that sleep deprivation negatively affects academic performance (78.8\%) and mood (78.4\%). Around 62.2 and $73.7 \%$ of students agreed that the demanding medical curriculum and stress of final exams lead to sleep deprivation, respectively. While $36.7 \%$ of students voiced the need for incorporation of curricular separate courses about healthy sleep patterns into medical curriculum, a much greater proportion of students (45.9\%) expressed interest in extracurricular activities about healthy sleep patterns. Interestingly, only $13.5 \%$ of students affirmed that they were counselled about sleep patterns and academic performance by their academic advisors. There were several statistically significant differences of means of students' perceptions according to gender, academic year and cGPA. Despite almost all academic advisors (95.5\%) asserted the importance of sleep patterns to academic performance, none (0 \%) inquired about sleep patterns when counselling students. Nineteen academic advisors (90.5\%) recommended incorporation of sleep patterns related learning into medical curricula; among those, only $1(n=1 / 19 ; 5.3 \%)$ recommended learning as a separate course whereas the majority $(n=18 / 19 ; 94.7 \%)$ recommended learning in forms of extracurricular activities and integration into relevant ongoing courses.
\end{abstract}

Conclusions: Our results showed that students had correct conceptions about the negative impact of sleep deprivation on academic performance and mood. Also, our results highlighted the need for curricular/extracurricular education and counseling about healthy sleep patterns.

Keywords: Sleep, Sleep duration, Perceptions, Medical students, Academic performance, Saudi Arabia

*Correspondence: aabuzaid@live.com

College of Medicine, Alfaisal University, Riyadh 11533, P.O. Box 50927,

Saudi Arabia 


\section{Background}

Sleep is essential for an individual's growth, health, learning and memory consolidation [1]. Sleep deprivation causes daytime sleepiness, reduced neurocognitive processing and impaired psychomotor performance [2]. Several studies have demonstrated a directly proportional correlation between suboptimal sleep duration (less than $7-8 \mathrm{~h}$ of sleep per night) and poor academic performance among college students [3-5].

The medical student population is believed to be at an increased risk for sleep deprivation [6-8]. This can be largely attributed to the altered lifestyles and overloaded academic commitments in order to cope with the demanding medical curriculum [7]. This constant burden, if not properly managed, may lead students to sleep deprivation and successively poor academic performance [9].

Despite students are the principal stakeholders impacted by sleep deprivation in medical schools [6-8], little is known about students' actual perceptions towards sleep deprivation and its relationship to academic performance. In line with the global tendency towards student-centered education [10], opinions from students provide worthy inputs to medical educators. These inputs are essential in rectifying misconceptions, implementing corrective mechanisms and planning the medical curriculum.

This study has three aims. The first aim is to explore the pre-clerkship students' overall perceptions towards sleep deprivation and its relationship to academic performance. The second aim is to explore possible differences of the perceptions according to gender, academic year and academic performance-expressed in cumulative grade point average (cGPA). The third aim is to explore the perceptions of academic advisors about sleep and related issues to academic performance, mentee-mentor counselling and curriculum design.

\section{Methods}

Design and setting

An online, anonymous, cross-sectional, self-rating (5-point Likert scale) study was conducted at Alfaisal University, College of Medicine, Riyadh, Saudi Arabia. The study took place from 19th March 2015 to 16th April 2015 in the spring of 2014-2015 academic year. The College offers a 6-year Bachelor of Medicine, Bachelor of Surgery (MBBS) program. The first 3 years are considered pre-clerkship years. This study was approved by the Institutional Review Board (IRB) at Alfaisal University (IRB Reference Number: 2015-067).

\section{Participants}

The targeted student subjects included all pre-clerkship first- and third-year medical students. The total number of students in the first- and third-year was 367 students. The reason for excluding the second-year students was due to the negligible response rates; they had back-toback a major end-of-block exam and two parallel courses mid-term exams at the time of study. The targeted academic advisor subjects included all academic advisors mentoring the first- and third-year students. The total number of academic advisors was 25 academic advisors.

\section{Survey}

Students were requested to voluntarily complete an online anonymous survey using the online tool KwikSurveys (Problem Free Company Ltd., Bristol, UK). The survey was administered to explore: (1) medical students' perceived perceptions towards sleep deprivation and its relationship to academic performance, (2) differences in students' perceptions according to gender, academic year and cGPA, and (3) academic advisors' inputs about sleep patterns and its relationship to academic performance.

Sleep deprivation was defined as less than $6 \mathrm{~h}$ of sleep per night [11], despite individual variations exist.

Two surveys were distributed. The first survey (Fig. 1) was distributed to students, and it was constructed partially based on a literature review (that is, published fact) and partially based on newly introduced survey questions that deemed important by the authors. The second survey was distributed to academic advisors (Fig. 2), and it was constructed fully based on newly introduced survey questions that deemed important by the authors. Afterwards, the students survey was peer-reviewed by two external in-house faculty members to verify its proper structure and content. Then it was pre-tested on a set of students $(n=20)$ to examine its validity and ensure proper interpretation of survey questions. Results of the pre-tested questions looked satisfactory and valid. Also, Cronbach's alpha coefficient test was used to measure the extent of internal consistency among the tested items. The overall Cronbach's alpha coefficient was 0.71 indicating acceptable internal reliability of the students survey data.

Students' characteristics data included: gender, academic year, and self-reported cGPA.

Academic performance was based on the self-reported cGPA, which is a common parameter to determine academic performance in sleep-related research [12, 13]. cGPA was categorized into: "good academic performance/high achievers" (GPA $\geq 3.0 / 4.0)$ and "poor academic performance/low achievers" (cGPA < 3.0/4.0). This dichotomous categorization was used in previous research for evaluation of the relationship between sleep and academic performance [12, 13].

The students' perceptions towards sleep deprivation and its relationship to academic performance were 


\section{$\underline{\text { Students Survey }}$}

Demographics (Please choose only one answer)

1. Gender:

○ Male

○ Female

2. Academic year:

○ First-year medical student

- Third-year medical student

3. Cumulative grade point average (cGPA):

- $\quad$ G $G P A<3.0 / 4.0$

- $\quad$ GGPA $\geq 3.0 / 4.0$

$\underline{\text { Students' perceptions towards sleep deprivation and its relationship to academic performance }}$

Please rate your level of agreement to the below statements:

"Sleep deprivation is defined as less than six hours of sleep per night"

\begin{tabular}{|c|c|c|c|c|c|}
\hline Evaluative Statement & Strongly Disagree & Disagree & Neutral & Agree & Strongly Agree \\
\hline 1. Sleep deprivation negatively affects my academic performance & & & & & \\
\hline 2. Sleep deprivation negatively affects my mood & & & & & \\
\hline 3. Stress of mid-term exams leads me to sleep deprivation & & & & & \\
\hline 4. Stress of final exams leads me to sleep deprivation & & & & & \\
\hline 5. The demanding medical curriculum leads me to sleep deprivation & & & & & \\
\hline 6. I'm interested in curricular individual courses about healthy sleep patterns & & & & & \\
\hline 7. I'm interested in extracurricular activities about healthy sleep patterns & & & & & \\
\hline 8. My academic advisor counsels me about sleep patterns & & & & & \\
\hline 9. I am knowledgeable about the healthy sleep patterns & & & & & \\
\hline
\end{tabular}

Fig. 1 Students survey

evaluated by the students' responses to a total of eight typical 5-point Likert rating scale evaluative statements, as follows: (1: strongly disagree, 2: disagree, 3 : neutral, 4: agree, and 5: strongly agree). The evaluative statements included perceptions of medical students towards sleep deprivation and its relationship to academic performance and its influential factors, such as: mood, course exam, medical curriculum and academic advisor.

The academic advisors' inputs about sleep patterns and its relationship to academic performance included questions related to: gender of academic advisor, frequency of counselling students about sleep patterns and the need for incorporation of sleep patterns related education into medical curriculum.

\section{Statistical analysis}

Regarding Likert scale responses, for the purposes of ease in reporting and analyzing data, disagreement responses $(1+2)$ were grouped as "disagree"; agreement responses $(4+5)$ were grouped as "agree"; and neutral responses (3) were presented as "neutral". The average 5-point Likert scale responses were presented as means \pm standard deviations (SD). All calculations of means \pm SDs for all evaluative survey statements were based on the 5-point Likert rating scale. Categorical data were presented as numbers and percentages. A two-tailed Mann-Whitney
$\mathrm{U}$ test was used to compare the average 5-point Likert scale responses across gender, academic year and cGPA. For all purposes, statistical significance was determined as a $\mathrm{p}$ value $<0.05$. All data were analyzed using the Statistical Package for Social Sciences version 22.0 (SPSS, Inc., Chicago, IL, USA).

\section{Results}

Two-hundred and fifty-nine students participated in the survey $(\mathrm{n}=259 / 367)$ with an overall response rate of $70.6 \%$. There were 117 (45.2\%) male students and 142 (54.8\%) female students. There were 158 (61.0\%) and 101 (39.0 \%) first- and third-year students, respectively. According to the dichotomous cGPA categorization, the vast majority of students were high achievers/good academic performance $(n=232 / 259 ; 89.6 \%)$ and only a minority were low achievers/poor academic performance $(\mathrm{n}=27 / 259 ; 10.4 \%)$.

Table 1 shows the students' overall perceptions towards sleep deprivation and its relationship to academic performance.

The vast majority of students agreed that sleep deprivation negatively affects academic performance $(78.8 \%)$ and mood (78.4\%). Around 62.2, 55.2, $73.7 \%$ of students agreed that the demanding medical curriculum, stress of mid-term exams and stress of final exams lead to sleep 
Academic Advisors Survey

Demographics

1. Gender (choose only one answer):

o Male

- Female

The perceptions of academic advisors about sleep and related issues to academic performance, mentee-mentor counseling, and curriculum design

1. Sleep patterns affect academic performance (choose only one answer):

○ Yes

- No

2. I counsel my students about sleep patterns (choose only one answer):

○ Yes

- No

3. I counsel my students about (you may choose more than one answer):

- Academic performance

- Sleep patterns

- Eating habits

- Learning styles

- Classroom attendance

- Problems with peers

- Problems with faculty

- Family issues

- Summer plans

4. Education about healthy sleep patterns should be incorporated into curriculum (choose only one answer):

o Yes

- No

5. Mode of incorporating sleep patterns education into curriculum should be (choose only one answer):

- Curricular separate courses

- Extracurricular activities and integration into ongoing courses

Fig. 2 Academic advisors survey

deprivation, respectively. While $36.7 \%$ of students voiced the need for incorporation of curricular separate courses about healthy sleep patterns into medical curriculum, a much greater proportion of students (45.9 \%) expressed interest in extracurricular learning activities about healthy sleep patterns. Only $13.5 \%$ of students affirmed that they were counselled about sleep patterns and academic performance by their academic advisors. Around $61.4 \%$ of students stated that they were knowledgeable about healthy sleep patterns.

Table 2 shows the differences of students' perceptions (self-reported Likert means) towards sleep and its relationship to academic performance according to gender, academic year and cGPA.

According to gender, there were statistically significant differences of means between male and female students regarding the following statements: "the demanding medical curriculum leads me to sleep deprivation" (3.5 vs. 3.9, respectively; $\mathrm{p}<0.01$ ), "I'm interested in extracurricular learning activities about healthy sleep patterns" (3.1 vs. 3.5 , respectively; $\mathrm{p}<0.02)$ and "my academic advisor counsels me about sleep patterns" (2.1 vs. 2.5, respectively; $\mathrm{p}<0.01$ ).

According to academic year, there was statistically significant difference of means between first- and thirdyear students regarding the following statement: "the demanding medical curriculum leads me to sleep deprivation" (3.6 vs. 3.9, respectively; $\mathrm{p}<0.01$ ).

According to cGPA, there were statistically significant differences of means between high and low achievers regarding the following statements: "stress of mid-term exams leads me to sleep deprivation" (3.5 vs. 4.0, respectively; $\mathrm{p}<0.02)$, "stress of final exams leads me to sleep deprivation" (3.9 vs. 4.6, respectively; p < 0.00 ) and "I'm interested in extracurricular learning activities about healthy sleep patterns" ( 3.2 vs. 4.0 , respectively; $\mathrm{p}<0.00$ ).

Table 3 shows the perceptions of academic advisors about sleep patterns and academic performance. Twenty-one academic advisors participated in the study $(\mathrm{n}=21 / 25)$ with a response rate of $84 \%$. There were 66.7 and $33.3 \%$ male and female academic advisors, respectively. Despite almost all academic advisors $(n=20 / 21$; 
Table 1 The students' overall perceptions towards sleep deprivation and its relationship to academic performance

\begin{tabular}{|c|c|c|c|c|}
\hline \multirow[t]{2}{*}{ Evaluative statement } & \multicolumn{4}{|c|}{ All respondents $(n=359)$} \\
\hline & $\begin{array}{l}\text { Disagree }^{a} \\
\text { n (\%) }\end{array}$ & $\begin{array}{l}\text { Neutral }^{\mathrm{a}} \\
\mathrm{n}(\%)\end{array}$ & $\begin{array}{l}\text { Agree }^{a} \\
\text { n (\%) }\end{array}$ & Mean $\pm S^{b}$ \\
\hline Sleep deprivation negatively affects my academic performance & $18(6.9)$ & $37(14.3)$ & $204(78.8)$ & $4.0 \pm 0.9$ \\
\hline Sleep deprivation negatively affects my mood & $12(5.0)$ & $43(16.6)$ & $203(78.4)$ & $4.1 \pm 0.9$ \\
\hline Stress of mid-term exams leads me to sleep deprivation & $51(19.7)$ & $65(25.1)$ & $143(55.2)$ & $3.5 \pm 1.2$ \\
\hline Stress of final exams leads me to sleep deprivation & $37(14.3)$ & $31(12.0)$ & $191(73.7)$ & $4.0 \pm 1.1$ \\
\hline The demanding medical curriculum leads me to sleep deprivation & $37(14.3)$ & $61(23.6)$ & $161(62.2)$ & $3.7 \pm 1.1$ \\
\hline I'm interested in curricular individual courses about healthy sleep & $52(20.1)$ & $112(43.2)$ & $95(36.7)$ & $3.3 \pm 1.1$ \\
\hline I'm interested in extracurricular learning activities about healthy sleep & $72(27.8)$ & $68(26.3)$ & $119(45.9)$ & $3.3 \pm 1.2$ \\
\hline My academic advisor counsels me about my sleep patterns & $156(60.2)$ & $68(26.3)$ & $35(13.5)$ & $2.3 \pm 1.1$ \\
\hline I am knowledgeable about the healthy sleep patterns & $33(12.7)$ & $67(25.9)$ & $159(61.4)$ & $3.7 \pm 1.0$ \\
\hline
\end{tabular}

SD standard deviation

a Disagreement responses (1: strongly disagree, and 2: disagree) were grouped as “Disagree"; agreement responses (4: agree, and 5: strongly agree) were grouped as "Agree"; and, neutral responses (3: neutral) were presented as "Neutral"

b The average 5-point Likert scale responses were presented as means \pm SD; all calculations of means \pm SDs for all evaluative statements were based on the 5-point Likert rating scale

$95.5 \%)$ asserted the importance of sleep patterns to academic performance, none $(0 \%)$ inquired about sleep patterns when counselling students. The most frequent aspects discussed during student counselling were: learning styles $(90.5 \%)$, classroom attendance $(85.7 \%)$ and summer plans $(81 \%)$. Nineteen academic advisors ( $\mathrm{n}=19 / 21 ; 90.5 \%$ ) recommended the incorporation of sleep patterns related learning into medical curricula; among those, only $1(\mathrm{n}=1 / 19 ; 5.3 \%)$ recommended introducing it as a separate course whereas the majority ( $\mathrm{n}=18 / 19$; $94.7 \%$ ) recommended learning in the forms of extracurricular activities and integration into relevant ongoing courses.

\section{Discussion}

Our study results are unique in three aspects. First, this study originated from Saudi Arabia (a largely genderconservative population) which would be of interest to researchers looking at cultural differences. Second, to the best of our knowledge, this is the first study from Saudi Arabia that endeavored to explore the subjective perceptions of medical students towards sleep deprivation and its relationship to academic performance. Third and most importantly, to the best of our knowledge, this is the first study to explore the perceptions of faculty academic advisors about sleep and related issues to academic performance, mentee-mentor counseling, and curriculum design.

Students generally do not recognize the negative impact of sleep deprivation on cognitive functioning and academic performance [14]. In our study, only a few students had misconceptions regarding the negative impact of sleep deprivation on academic performance [9] and mood [14]. Of note, the effect of sleep deprivation on performance was studied in a meta-analysis and results showed that mood was actually more affected by sleep deprivation than either cognitive or motor performance [14]. Therefore, this issue should be critically considered since an individual's mood is a core determinant of daytime functioning, physical vitality, productivity, decision making, mental sharpness and retention of knowledge.

Striving for excellent academic achievement is one of the top explanations why medical students may modify their total sleep hours per night in college [14]. The most likely modification is sleep deprivation [6-8] in order to meet the continuous pressured academic demands of overloaded curriculum and nerve-racking exams [12].

Female students had higher mean self-reported cGPA than male students (3.7 vs. 3.2, respectively). Sleep deprivation is expected to be higher in female students as they are generally considered high achievers (academically) when compared to their male counterparts [15, 16]; hence, they are more likely to sacrifice hours of sleep to endeavor towards achieving excellent academic performance which is vital to securing postgraduate and employment opportunities.

Furthermore, sleep deprivation is expected to be higher in senior students when compared to junior students as the burden of medical curriculum increases as students dive deeper into medicine and experience the introductory transition to the clinical more demanding education.

Moreover, sleep deprivation is expected to be higher in the low achievers population who possess relatively less cognitive learning skills that likely require them to cut 


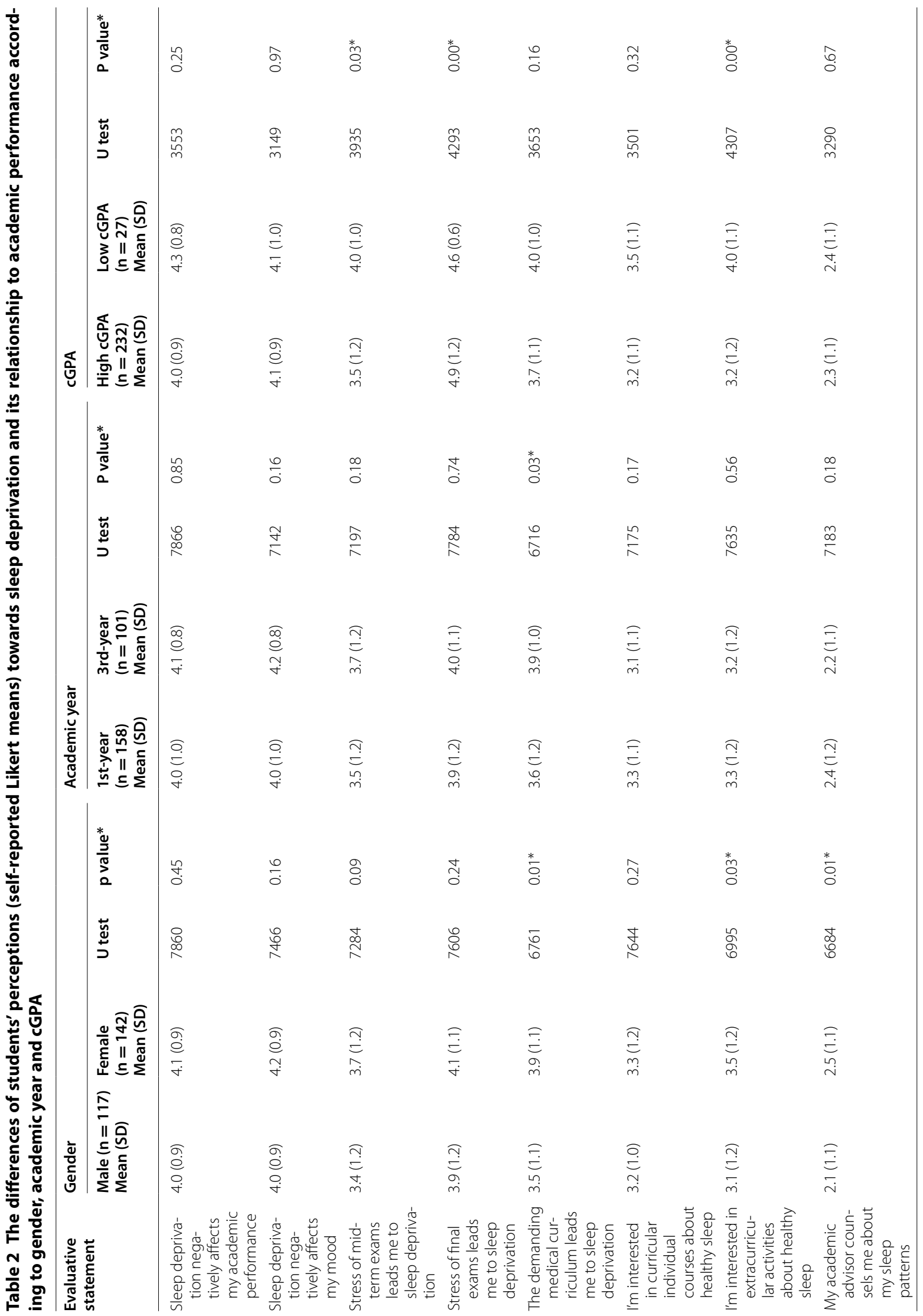




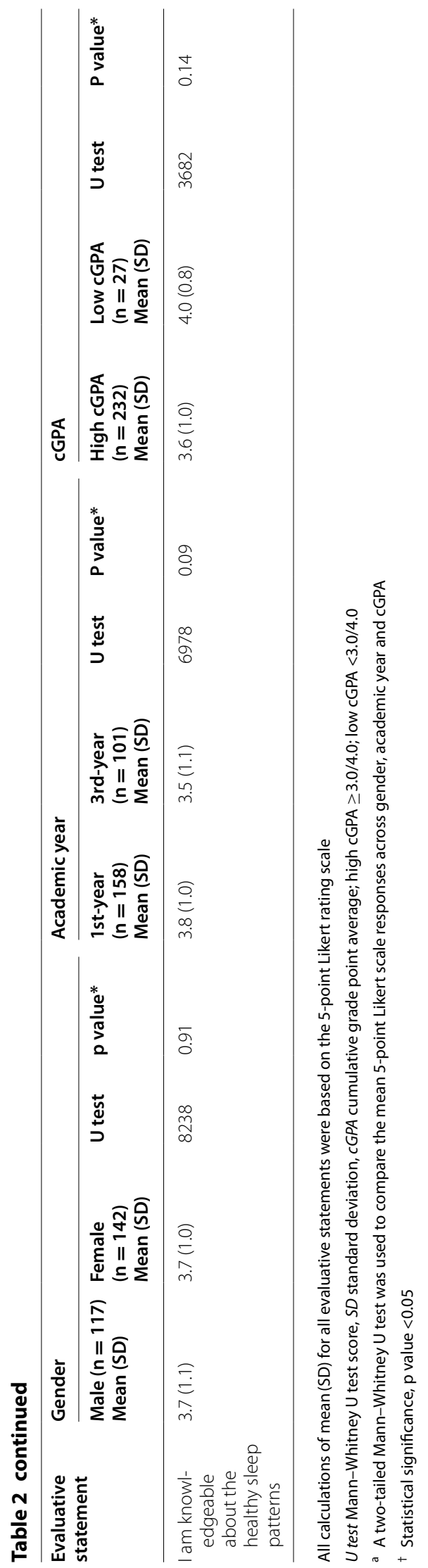


Table 3 The perceptions of academic advisors about sleep and related issues to academic performance, menteementor counselling and curriculum design

\begin{tabular}{|c|c|}
\hline & n (\%) \\
\hline \multicolumn{2}{|l|}{ Gender $(n=21)$} \\
\hline Male & $14(67.3$ \\
\hline Female & $7(33.3)$ \\
\hline \multicolumn{2}{|l|}{ Sleep patterns affect academic performance $(n=21)$} \\
\hline Yes & $20(95.5$ \\
\hline No & $1(4.5)$ \\
\hline \multicolumn{2}{|l|}{ I counsel my students about sleep patterns $(n=21)$} \\
\hline Yes & $0(0)$ \\
\hline No & $100(0)$ \\
\hline \multicolumn{2}{|l|}{ I counsel my students about $(n=21)$} \\
\hline Academic performance & $21(100)$ \\
\hline Sleep patterns & $0(0)$ \\
\hline Eating habits & $3(14.3)$ \\
\hline Learning styles & $20(90.5$ \\
\hline Classroom attendance & $18(85.7$ \\
\hline Problems with peers & $4(19)$ \\
\hline Problems with faculty & $6(28.6)$ \\
\hline Family issues & $12(57.1$ \\
\hline Summer plans & $17(81.0$ \\
\hline \multicolumn{2}{|l|}{$\begin{array}{l}\text { Education about healthy sleep patterns should be incorporated into } \\
\text { curriculum }(n=21)\end{array}$} \\
\hline Yes & $19(90.5$ \\
\hline No & $2(9.5)$ \\
\hline \multicolumn{2}{|c|}{$\begin{array}{l}\text { Mode of incorporating sleep patterns education into curriculum should } \\
\text { be }(n=19)\end{array}$} \\
\hline Curricular separate courses & $1(5.3)$ \\
\hline Extracurricular activities and integration into ongoing courses & $18(94.7$ \\
\hline
\end{tabular}

back on total sleep hours in order to meet the demands for additional studying time and better exam preparation. A study has shown that low achievers are likely to expect low grades and hence experience greater degree of stress that simultaneously results in worse sleeping patterns such as sleep deprivation [17]. This will eventually negatively influence exam preparation and performance. Daytime sleepiness is a probable result of sleep deprivation $[9,13]$. Daytime sleepiness-as assessed by Epworth Sleepiness Scale (ESS) - was found to be higher in low achieving students than high achieving students in several studies [12, 13].

Students preferred extracurricular over curricular educational interventions to enrich their deficient knowledge about healthy sleep habits. This preference could be attributed to the fact that students do not want to further encumber their already demanding medical curriculum; incorporation of curricular separate (stand-alone) courses would cause an increased burden and study load, which might affect their cGPA negatively. Much emphasis on students' health related issues, particularly healthy sleep habits, during medical school is greatly needed and should not be neglected. Along the lines of student-centered education, students' inputs should be valued and honored [10]. A plausible solution to avoid adding separate sleep related courses is a well-designed integration of such learning objectives into ongoing courses such as, physiology, community medicine, public health and family medicine. Furthermore, as suggested by students, extracurricular educational activities about healthy sleep habits should be initiated, in forms of elective courses, interactive workshops, informative on-campus lecture series by experts in the field, and one-to-one dialogues with sleep medicine professionals and others.

It is very worrisome that students are not being counselled about healthy sleeping habits and academic performance by their academic advisors, despite asserting its importance. The unawareness and underestimation of educators of the negative influence of sleep deprivation on cognitive functioning and academic performance has been reported before [14], particularly for the low achieving students. The roles of academic advisors should expand further and refrain from merely discussing learning styles, classroom attendance, problems with individuals, and summer plans to include discussing the often neglected (hidden) issues influencing academic performance; one of which is highlighting the significance of sufficient sleep duration (during weekdays, weekends and before exams) to their academic performance and advancement in medical school [12], particularly for the low achieving students. The Student Affairs departments in medical schools should play key roles in educating their institutions' academic advisors about healthy sleep habits needed to adequately counsel the medical students.

Several limitations to our study are present. First, this is a self-reported designed study and therefore results are vulnerable to overestimation and/or underestimation by the students. Second, the response rate was less than expected which may have impacted the validity of study. Third, the definition of sleep deprivation variable (less than $6 \mathrm{~h}$ per night) was not clearly specified in the survey as whether including workdays and weekends, or most nights or some nights per week/month. It is known that undergraduate students have differences regarding the nocturnal sleep duration in weekdays and weekends.

\section{Conclusion}

In conclusion, our results showed that students had correct conceptions about the negative impact of sleep deprivation on academic performance and mood. Additionally, the study highlighted the need for curricular/ extracurricular education and counselling about healthy 
sleep habits. Future studies are needed to explore other factors leading to sleep deprivation other than the academic environment. Additional future studies include planning and implementing appropriate curricular and extracurricular activities to improve academic performance by targeting the students' sleep patterns (habits). These are interesting arenas for future research as they are barley explored in literature, particularly in developing countries.

\section{Abbreviation}

cGPA: cumulative grade point average.

\section{Authors' contributions}

LA: conception, design, data collection, data analysis and manuscript writing; JS, SK, KK: design, data collection and manuscript writing; AO: design, manuscript editing and revising for intellectual content; AA: conception, design, data analysis, manuscript writing and revising for intellectual content. All authors read and approved the final manuscript.

\section{Source of fund}

None.

\section{Competing interests}

The authors declare that they have no competing interests.

Received: 10 June 2015 Accepted: 25 November 2015

Published online: 01 December 2015

\section{References}

1. Fenn KM, Hambrick DZ. Individual differences in working memory capacity predict sleep-dependent memory consolidation. J Exp Psychol Gen. 2012;141(3):404-10.

2. Aldabal L, Bahammam AS. Metabolic, endocrine, and immune consequences of sleep deprivation. Open Respir Med J. 2011;5:31-43.

3. Gaultney JF. The prevalence of sleep disorders in college students: impact on academic performance. J Am Coll Health. 2010;59(2):91-7.

4. Gomes AA, Tavares J, de Azevedo MH. Sleep and academic performance in undergraduates: a multi-measure, multi-predictor approach. Chronobiol Int. 2011;28(9):786-801.
5. Gilbert SP, Weaver CC. Sleep quality and academic performance in University students: a wakeup call for college psychologists. J Coll Stud Psychother. 2010;24(4):295-306.

6. Veldi M, Aluoja A, Vasar V. Sleep quality and more common sleep related problem in medical students. Sleep Med. 2005;6(3):269-75.

7. Bahammam AS, Al-Khairy OK, Al-Taweel AA. Sleep habits and patterns among medical students. Neurosciences (Riyadh). 2005;10(2):159-62.

8. Loayza HM, Ponte TS, Carvalho CG, Pedrotti MR, Nunes PV, Souza CM, et al. Association between mental health screening by self-report questionnaire and insomnia in medical students. Arq Neuropsiquiatr. 2001;59(2-A):180-5.

9. Wolfson AR, Carskadon MA. Understanding adolescents'sleep patterns and school performance: a critical appraisal. Sleep Med Rev. 2003;7(6):491-506.

10. Abu-Zaid A. Research skills: the neglected competency in tomorrow's 21st-century doctors. Perspect Med Educ. 2014;3(1):63-5.

11. Shlisky JD, Hartman TJ, Kris-Etherton PM, Rogers CJ, Sharkey NA, NickolsRichardson SM. Partial sleep deprivation and energy balance in adults: an emerging issue for consideration by dietetics practitioners. J Acad Nutr Diet. 2012;112(11):1785-97.

12. Abdulghani HM, Alrowais NA, Bin-Saad NS, Al-Subaie NM, Haji AM, Alhaqwi Al. Sleep disorder among medical students: relationship to their academic performance. Med Teach. 2012;34(Suppl 1):S37-41.

13. Bahammam AS, Alaseem AM, Alzakri AA, Almeneessier AS, Sharif MM. The relationship between sleep and wake habits and academic performance in medical students: a cross-sectional study. BMC Med Educ. 2012;12:61.

14. Pilcher JJ, Huffcutt Al. Effects of sleep deprivation on performance: a meta-analysis. Sleep. 1996;19(4):318-26.

15. Salem RO, Al-Mously N, Nabil NM, Al-Zalabani AH, Al-Dhawi AF, Al-Hamdan N. Academic and socio-demographic factors influencing students' performance in a new Saudi medical school. Med Teach. 2013;35(Suppl 1):S83-9.

16. Zhou YX, Zhao ZT, Li L, Wan CS, Peng CH, Yang J, et al. Predictors of firstyear GPA of medical students: a longitudinal study of 1285 matriculates in China. BMC Med Educ. 2014;14:87.

17. Ahrberg K, Dresler M, Niedermaier S, Steiger A, Genzel L. The interaction between sleep quality and academic performance. J Psychiatr Res. 2012;46(12):1618-22

Submit your next manuscript to BioMed Central and we will help you at every step:

- We accept pre-submission inquiries

- Our selector tool helps you to find the most relevant journal

- We provide round the clock customer support

- Convenient online submission

- Thorough peer review

- Inclusion in PubMed and all major indexing services

- Maximum visibility for your research

Submit your manuscript at www.biomedcentral.com/submit

C Biomed Central 